\title{
Cardiovascular Complications of COVID-19 Infection
}

\section{Complicações Cardiovasculares Associadas à Infeção por COVID-19}

\author{
Maria TRÊPA $\bigotimes^{1,2,3}$, António HIPÓLITO REIS ${ }^{1,4}$, Mário OLIVEIRA ${ }^{5,6,7}$ \\ Acta Med Port 2021 Sep;34(9):608-614 - https://doi.org/10.20344/amp.15584
}

ABSTRACT

Introduction: Reports of cardiovascular complications related to the COVID-19 infection have been frequent.

Methods: Narrative review for relevant articles on the topic. The classic cardiovascular risk factors, like age, obesity, diabetes, and hypertension are associated with adverse outcomes in COVID-19 patients. Cardiovascular complications can have a diverse clinical presentation including silent myocardial injury, acute coronary syndromes, thromboembolism, cardiac arrhythmias, and heart failure. There are multiple mechanisms of cardiac injury that are not mutually exclusive. The approach to diagnosis and management should be carried out according to usual practice, while considering the particularities of COVID-19 infection.

Conclusion: The interaction between SARS-CoV-2 and the heart is complex and is manifested in multiple ways. Regardless of the clinical presentation, cardiac complications convey a worse prognosis. Patients should be actively monitored and treated accordingly. Keywords: Arrhythmia; COVID-19; Heart Failure; Myocardial Infarction; Pulmonary Embolism; SARS-CoV-2

\section{RESUMO}

Introdução: As complicações cardiovasculares associadas a infeção por COVID-19 têm sido frequentemente reportadas.

Métodos: Revisão da literatura sobre os artigos relevantes neste tópico. Os fatores de risco cardiovasculares clássicos como idade, obesidade, diabetes e hipertensão foram associados a um risco maior de evolução desfavorável. As complicações cardiovasculares podem ter uma apresentação clínica variável incluindo lesão miocárdica, síndrome coronário agudo, trombo-embolismo, arritmias e insuficiência cardíaca. Estão descritos múltiplos mecanismos de lesão cardíaca os quais não são mutualmente exclusivos. A abordagem diagnóstica e terapêutica deve seguir a prática comum tendo, no entanto, em consideração as particularidades da infeção por COVID-19.

Conclusão: A interação entre a infeção por COVID-19 e o coração é complexa e manifesta-se de várias formas. Independentemente da apresentação clínica, as complicações cardíacas conferem um prognostico desfavorável pelo que devem ser monitorizadas ativamente e tratadas de forma apropriada.

Palavras-chave: Arritmia; COVID-19; Embolia Pulmonar; Enfarte do Miocárdio; Insuficiência Cardíaca

\section{INTRODUCTION}

As of the $1^{\text {st }}$ of March of 2021, almost one year after the World Health Organization declared the COVID-19 viral infection as a pandemic, there were more than 113 million cases reported worldwide. The current global case fatality rate is $2.2 \% .^{1,2}$ Cardiovascular disease and risk factors like obesity, diabetes and hypertension are associated with an increased risk of adverse outcomes from COVID-19 infection. ${ }^{3}$ In a recent meta-analysis, the intensive care unit admission rate was $10.9 \% .^{4}$ The typical presentation of severe COVID-19 infection is viral pneumonia. However, the clinical picture varies widely, from asymptomatic or mild flu-like symptoms to acute respiratory distress syndrome (ARDS) and multisystemic complications. Cardiovascular complications of COVID-19 infection are being reported more frequently and range from silent myocardial injury to acute coronary syndromes, thromboembolic events, arrhythmia, and cardiogenic shock.

The purpose of this clinical review is to merge current data on the most common cardiovascular complications as- sociated to COVID-19 infection and their underlying mechanisms. Bearing in mind the evolving nature of this topic, and the present knowledge gaps, we aim to provide a clinical update of the most recent evidence.

\section{METHODS}

A narrative review using PubMed was conducted using the keywords 'COVID-19' or 'SARS-CoV-2' along with 'cardiovascular', 'cardiac', 'arrhythmia', 'myocardial injury', 'myocardial infarction', 'pulmonary embolism', 'out-of-hospital-cardiac-arrest' and 'heart failure'. Prospective and retrospective studies, reviews, meta-analysis, clinical guidelines, guidance documents and case reports, were included. Relevant articles published in English were screened and included only after critical review.

\section{Risk factors for severe COVID-19 infection}

Classic cardiovascular risk factors, namely, hypertension, diabetes and obesity, are frequent comorbidities in

1. Serviço de Cardiologia. Centro Hospitalar Universitário do Porto. Porto. Portugal.

2. Serviço de Cuidados Intensivos. Centro Hospitalar Universitário do Porto. Porto. Portugal.

3. Cardiovascular Research Group. Unidade Multidisciplinar de Investigação Biomédica. Instituto de Ciências Biomédicas Abel Salazar. Universidade do Porto. Porto. Portugal.

4. Departamento de Medicina. Instituto de Ciências Biomédicas Abel Salazar. Universidade do Porto. Porto. Portugal.

5. Serviço de Cardiologia. Centro Hospitalar Universitário Lisboa Central. Lisboa. Portugal.

6. Centro do Coração e Vasos. Hospital CUF Tejo. Lisboa. Portugal.

7. Instituto de Fisiologia e Centro Cardiovascular. Faculdade de Medicina. Universidade de Lisboa. Lisboa. Portugal.

$\triangle$ Autor correspondente: Maria Trêpa. Maria trp@hotmail.com

Recebido: 22 de dezembro de 2020 - Aceite: 12 de abril de 2021 - Online issue published: 01 de setembro de 2021

Copyright $\odot$ Ordem dos Médicos 2021 
COVID-19 patients and convey an increased risk for adverse outcomes. ${ }^{5-9}$ The prevalence of hypertension ranged from $15 \%-17 \%$ in the Chinese population, 5,6 to $56 \%$ in the New York study. ${ }^{9}$ Diabetes was present in $7 \%$ and $17 \%$, respectively. Previous cardiovascular disease was reported in $14 \%$ to $35 \%$ of patients, ${ }^{9,10}$ with one study specifically reporting that coronary artery disease was present in $2.5 \%$ of the overall population and $9 \%$ of the critically ill patients. ${ }^{5}$

The presence of these comorbidities confers an increased risk of developing severe forms of COVID-19 infection: the New York study highlighted obesity as a significant risk factor for mechanical ventilation. ${ }^{9}$ A meta-analysis found that cardio or cerebrovascular disease increased the risk of developing severe manifestations of COVID-19 three-fold. ${ }^{6}$ In a nationwide Danish study, risk factors for death included age [odds ratio (OR) 15 (95\% Cl 7.6 - 24) for 70 - 79 years, when compared with the 50 - 59 years age group], male sex, comorbidities and chronic diseases. ${ }^{8}$ Likewise, the presence of ischemic heart disease and heart failure (HF) increased the risk of hospitalization (OR 1.4, 95\% Cl $1.2-$ 1.7 ) and $2.295 \% \mathrm{Cl} 1.7-2.9$, respectively).

\section{Pathophysiological mechanisms}

There is consensus that endothelial dysfunction is the final and most relevant pathological lesion caused by COVID-19 infection. ${ }^{11-14}$ The SARS-CoV-2 virus enters host cells via angiotensin conversion enzyme 2 (ACE 2) receptors on the cellular membrane, which is abundant in the lungs, heart and vessels. The SARS-CoV-2 virus triggers a generalized inflammatory response, via dysregulation of multiple pathways that coordinate host defence systems and homeostasis. In severe cases, patients can develop a feedback loop that perpetuates inflammation and aggravates endothelial damage. ${ }^{11}$

Mechanisms of cardiac injury include cytokine-mediated immune activation, direct cardiotoxicity, micro and macrovascular dysfunction, and hypercoagulability. The risk of myocardial injury is significant and multifactorial, either by destabilization of coronary plaques, vasospasm, thromboembolic events, hypoxic lesion leading to type 2 myocardial infarction (MI), catecholamines-induced cardiomyopathy or myocarditis. ${ }^{12-14}$

From a hemodynamic standpoint, COVID-19 infection causes multiple pressure and volume changes that directly affect the heart. Severe pulmonary infection increases pulmonary pressures and therefore right ventricle (RV) afterload. Positive pressure ventilation also increases RV afterload and decreases venous return (RV preload). The RV responds by increasing contractility and dilating to increase its end-diastolic volume and thus its stroke volume (Frank-Starling law). However, it fares poorly with acute increases in pressure and these mechanisms can quickly fail. The systemic cardiac output can be compromised both by decreased left ventricle (LV) preload (due to decreased venous return, $\mathrm{RV}$ failure and paradoxical septal movement that reduces LV filling in diastole) and impaired LV contractility caused by hypoxia, inflammation, or other 'direct' car- diac injuries, like coronary occlusion, spasm or myocarditis.

Severe inflammation can also occur, causing vasoplegia, and manifesting with hypotension. On a physiological level, decreased systemic vascular resistance, combined with changes in capillary permeability, lead to fluid leaks to the extravascular compartment and cause reduction in venous return, as well as edema.

Low cardiac output combined with hypotension can cause impairment in end-organ perfusion, which is required to define shock. In the kidneys, low perfusion will activate the renin-angiotensin-aldosterone system (RAAS). The failing heart cannot cope with the extra fluid retention and increased end-diastolic pressures induced by the RAAS and enters a deleterious loop that potentiates shock development.

In patients with severe pulmonary infection and ARDS, endothelial dysfunction leads to inflammatory lung edema, reduced lung compliance and ventilation/perfusion mismatch. If there is associated HF, the increase in end-diastolic pressure will be transmitted to the lung causing transudative edema. The 'cardiogenic' edema in a patient with severe lung injury compromises even further gas exchange and lung compliance.

\section{Cardiac complications of COVID-19 infection Myocardial injury}

Myocardial injury in infected patients can occur by the multiple mechanisms mentioned earlier. It is expressed quantitatively by the release of troponin. Troponin elevation occurs in $17 \%$ to $22 \%$ of hospitalized patients with COVID-19 infection. ${ }^{15,16}$ Myocardial injury is not a clinical diagnosis in itself, but troponin elevation is related to adverse prognosis in early observational studies. ${ }^{10,16}$ A subsequent study using Cox regression found an increased risk of death in patients with cardiac injury [HR 4.2 (95\% Cl, 1.92 - 9.49)]. ${ }^{15}$ A review suggests monitoring troponin at baseline for all patients, and then every 48 hours in intermediatehigh risk patients. While this might help risk stratification and provide clues to a potential cardiac complication, the document also emphasizes the need for good clinical judgment when interpreting the results. ${ }^{17}$

\section{Myocarditis}

The diagnosis of myocarditis involves well defined criteria from four different aspects: symptoms, EKG, troponin elevation and imaging [echocardiography and cardiac magnetic resonance (CMR)]. ${ }^{18}$ Coronary disease should be discarded in all patients with suspected myocarditis. Endomyocardial biopsy is a class I indication in persisting severe $\mathrm{HF}$ and fulminant myocarditis.

In COVID-19 patients, myocarditis can be challenging to diagnose due to overlapping symptoms (dyspnoea and chest pain from either cardiac or pulmonary origin) and difficulties in obtaining CMR, which is of paramount importance to confirm the diagnosis.

Considering the pathophysiology of the COVID-19 infection, especially in critically ill patients, it is likely that 
myocarditis is more prevalent than reported. The underlying specific mechanisms of COVID-19 myocarditis are not clearly defined, although they are thought to be mediated by activated T-cells and macrophages that infiltrate the myocardium. ${ }^{12,13}$ The cytokine storm phase of COVID-19 infection further increases the risk of severe cardiac damage and arrhythmias. Furthermore, a high viral load has been associated with fulminant myocarditis in these patients. ${ }^{19} \mathrm{~A}$ meta-summary of cases found 12 examples of CMR or biopsy proven COVID-19 myocarditis in the literature. ${ }^{20}$ The most common symptoms were fever, dyspnoea and chest pain. EKG changes included T-wave changes and ventricular tachycardia. LV dysfunction was also frequent. Severe myocarditis was associated with cytokine storm. Patients were treated with drugs for HF, as well as a variety of immunosuppressants, glucocorticoids and IV immunoglobulins..$^{21,22}$ However, none of these treatments has been tested in specific trials.

The timing of presentation is currently uncertain, with reports of symptoms weeks after the COVID-19 infection. ${ }^{23}$ Furthermore, histological evidence of COVID-19 inside the cardiomyocyte is unavailable, although one report found viral particles outside the cardiomyocytes. ${ }^{24}$

\section{Acute coronary syndrome}

Acute coronary syndrome (ACS) may be the initial presentation of COVID-19 or may complicate the course of an infected patient. Data is scarce about the incidence of ACS prompted by COVID-19 infection.

Importantly, the general ACS admission rate (non-COVID related) during the first wave of the pandemic, decreased up to $54 \%$ according to an international report. ${ }^{25}$ Likewise, a reduction in coronary angiography and other diagnostic tests was noted. ${ }^{26}$ Possible reasons for this include late admissions of patients due to fear of coming to the hospital and overwhelmed healthcare systems with decreased capacity to provide care. A 30 minute increase in door-toguidewire time was also found in one study. ${ }^{27}$ Difficulties in defining circuits for COVID-19 patients and managing the additional time needed for personnel and catheterization laboratory preparation contribute to the delays. The decrease in procedures was more substantial in low to middle income countries. ${ }^{26}$ Adverse outcomes like in-hospital death, cardiogenic shock, ventricular arrhythmias and need for mechanical support were also more common during the first wave. ${ }^{27}$

Clinical presentation of suspected ACS in COVID-19 patients may range from ST-elevation $\mathrm{Ml}$ to $\mathrm{MI}$ with nonobstructive coronary arteries (known as MINOCA, which is a working diagnosis for multiple possible causes from myocarditis to coronary dissection) and type $2 \mathrm{Ml}$ (which is typically caused by a mismatch between oxygen supply and demand, and not related to an acute coronary plaque event like ACS). As for angiographic findings, several studies found a higher prevalence of nonobstructive disease from $33 \%$ to $40 \%$ in those who underwent cardiac catheterization for suspected ST-elevation Ml. ${ }^{28,29}$
In patients with unclear diagnosis, close clinical monitoring and serial EKG and troponin measurements should be performed. EKG changes over time, the pattern of rise in cardiac biomarkers as well as segmental wall changes in echocardiography are critical to define the best course of action.

Management of ACS should follow the appropriate guidelines for ST-elevation and non-ST elevation coronary syndromes. The European Society of Cardiology (ESC) has developed a guidance document with useful practical considerations in the specific context of the COVID-19 pandemic. ${ }^{14}$ For ST-elevation MI, all efforts must be employed to achieve primary percutaneous coronary intervention $(\mathrm{PCl})$ as soon as possible. Fibrinolysis is reserved for eligible patient who cannot timely reach a $\mathrm{PCl}$ centre. For nonST elevation MI patients with intermediate risk (diabetes, renal insufficiency, early post-infarction angina or previous $\mathrm{PCl}$ or coronary bypass) the ESC guidance document suggests considering non-invasive testing, depending on availability and expertise.

\section{Heart failure}

Data on acute HF prevalence in COVID-19 patients is limited. Zhou et al found that $23 \%$ of hospitalized patients developed symptoms of HF and was associated with poorer prognosis. ${ }^{16}$

As for ACS, a striking decrease in the admission rate for HF during the first wave was noticed. ${ }^{30,31}$ This raises concerns for patient safety and potential adverse outcomes. However, the specific consequences and impact in HF patients are not yet reported. Telemedicine programs have been suggested as an effective tool to help mitigate this issue. ${ }^{32}$

The underlying causes for acute HF in the COVID-19 patient are numerous and not mutually exclusive. These include ARDS, hypoxic lesions, hypervolemia, cardiorenal syndromes and pulmonary embolism, but also specific cardiac complications, such as Ml, myocarditis, stress-induced cardiomyopathy and arrhythmias..$^{14,33,34}$ Furthermore, any of these mechanisms can result in an acute decompensation of a chronic HF patient.

Defining hemodynamic profiles is more important for the management of the COVID-19 critical patient than phenotypical HF classifications (reduced or preserved ejection fraction). Integrating clinical assessment with laboratory values, EKG and echocardiographic findings is key, both to identify reversible causes that require specific treatment (like ACS or arrhythmia) and to define the best therapeutic strategy. ${ }^{34}$ Meticulous assessment of volume status and perfusion should be done using multiple parameters: clinical (peripheral perfusion, edema, pulmonary congestion, urinary output, central venous pressure), laboratory (cardiac biomarkers, central venous $\mathrm{O}_{2}$ saturation, lactate, markers of liver and renal dysfunction) and imaging (mainly cardiac and pulmonary ultrasound). Hypervolemia is best managed with diuretics (while also avoiding hypovolemia, especially in vasoplegic states and in RV failure). 
If cardiogenic shock ensues, starting inotropes with pulmonary vasodilatory properties may be useful. In low blood pressure states, especially with compromised renal perfusion and congested venous system, vasopressors are often necessary. HF drugs should be carefully considered in each case. Measurement of NT-proBNP is useful and has prognostic value. ${ }^{35}$

Of note, despite initial controversies with the use of ACE-inhibitors, several large cohort studies, ${ }^{36,37}$ and a randomized trial ${ }^{38}$ have found no association between ACE inhibitors and adverse outcomes.

\section{Stress cardiomyopathy}

Stress cardiomyopathy (stress CMP) or Takotsubo syndrome has rarely been reported as a complication of COVID-19 infection. In a case series, ${ }^{39} 16$ reports were found in the literature. Both genders were equally affected and mean age was 57 years. Most patients had reduced LV ejection fraction and three patients died. These characteristics differ from non-COVID-19 related stress CMP that typically affect postmenopausal women and rarely causes death. Interestingly, some studies have reported also an increase in stress CMP in non-infected patients. A Cleveland clinic study of patients with suspected ACS and a negative test for COVID-19, found a 4.58-fold increase in stress CMP compared to the pre-pandemic period. ${ }^{40}$

Stress CMP is characterized by reversible ventricular dysfunction, and the most typical pattern is 'apical ballooning' with akinesia of all distal segments of the LV walls. It is usually caused by an emotional or physical trigger. Evaluation of coronary disease is mandatory in all patients, by coronary angiography or computed tomography (CT). ${ }^{41} \mathrm{Ac}-$ cepted pathological mechanisms for stress CMP include high circulating catecholamine levels, exaggerated inflammatory response and direct cytotoxicity. ${ }^{39,41}$

Treatment depends on the severity of presentation and is mainly supportive. In cardiogenic shock, non-aminergic inotropic drugs may be a good option. However, in some cases, patients can develop an obstruction of the LV outflow tract due to hypercontractility of the basal portions. In this scenario, the use of inotropes may be counterproductive. ${ }^{42}$

\section{Pericarditis and pericardial effusion}

Isolated pericarditis has been infrequently reported in relation with COVID-19 infection. However, pericardial effusion accompanying myocarditis has been reported in up to $50 \%$ of cases..$^{20}$ In the available case reports for isolated pericarditis, the first clue to the diagnosis was the typical chest pain. ${ }^{43,44}$ Evolution was usually benign. Regarding treatment, experts recommend maintaining colchicine, while reserving ibuprofen for worsening pain. For fever and other systemic symptoms, paracetamol is preferred. Furthermore, corticosteroids and anakinra (a recombinant modified version of the interleukin one receptor antagonist protein) can be considered to treat both situations. ${ }^{45}$

\section{Cardiac arrhythmias}

Cardiac arrhythmias have been described in $17 \%$ of the hospitalized cases and in almost $50 \%$ of patients in the intensive care units. ${ }^{46}$ Cardiac arrhythmias probably contribute to a higher risk of adverse outcomes, with an increased risk of in-hospital death, and varies from bradyarrhythmia (less common), to sinus tachycardia and atrial arrhythmias (the most frequently reported), like atrial fibrillation (AF) and atrial flutter, and ventricular dysrhythmias, including cardiac arrest. ${ }^{47}$ In infected hospitalized patients, continuous EKG monitoring and accurate and prompt recognition of arrhythmias are important.

AF is one of the common chronic comorbidities found in patient deaths due to COVID-19. ${ }^{48}$ In a large propensity score matched study of COVID-19 patients aged over 50 years of age, AF significantly increased short-term mortality and thromboembolic events. ${ }^{49}$

Risk factors for the development of cardiac arrhythmias are: 1 . Respiratory failure, 2. myocardial ischemia or myocarditis, 3. cardiogenic shock, 4. sepsis or systemic inflammation, 5 . hyperactivity of sympathetic nervous system, 6 . hypercoagulability status, 7 . electrolyte disturbances, 8. Therefore, the incidence of cardiac arrest and cardiac arrhythmias in patients with COVID-19 are likely the consequence of systemic illness and not solely the direct effect of the viral infection. In a study assessing the QT interval in COVID-19 patients, the hydroxychloroquine-azithromycin combination regimen was not associated with arrhythmic fatalities and none of the deceased had a QTC over 500 ms. ${ }^{50}$ In an early report from Guo et al, among 187 patients with COVID-19 from a Chinese cohort, 5.9\% had ventricular tachyarrhythmias while hospitalized. ${ }^{10}$

\section{Out-of-hospital cardiac arrest}

Since the onset of the COVID-19 pandemic an increase in the incidence of out-of-hospital-cardiac-arrest (OHCA) has been consistently reported worldwide. ${ }^{51-54}$ In an Italian study, COVID-19 diagnosis accounted for around $80 \%$ of these events. ${ }^{51}$ This rise in OHCA is presumably due to a combination of acute respiratory failure and pulmonary embolism associated with COVID-19, and arrhythmic sudden death due to myocardial injury and QT interval prolongation (infection-related or caused by administration of drugs to treat the infection). OHCA has been accompanied by a reduction in survival from resuscitation efforts. Potential causes include delay in seeking medical care, longer waiting times for emergency services, fewer shockable rhythms and lower rates of bystander initiated cardiopulmonary resuscitation.

\section{Pulmonary embolism}

Pulmonary embolism (PE) is one of the most severe thromboembolic manifestations. Recent studies report overall incidences of PE in COVID-19 patients between $1.1 \%-3.4 \%,{ }^{55,56}$ but rising up to $17 \%-27 \%$ in critical patients. ${ }^{57,58}$ In an autopsy study, PE was the direct cause of death in $33 \%$ of COVID-19 patients. ${ }^{59}$ These rates are 
higher than previous reports for other infections. For instance for H1N1 influenza, the rate of venous thromboembolism was approximately $6 \% .{ }^{60}$ The mechanism of thromboembolic events in COVID-19 infection is not fully understood, but all three components of the Virchow triad (endothelial injury, stasis, and hypercoagulable state) are thought to play a major role in thrombus formation. Coagulation abnormalities are frequent in COVID-19 patients, ${ }^{61,62}$ and are associated with adverse outcomes. ${ }^{62,63}$ Remarkably, deep venous thrombosis (DVT) has seldom been reported as the cause for PE. Although this might be partially explained by suboptimal screening, some studies suggest that pulmonary in situ thrombosis instead of embolism is also present. ${ }^{64}$

Several expert consensus agree on the following recommendations ${ }^{62,65-68:}$ 1. Thromboprophylaxis (mechanical or pharmacological) in hospitalized patients; 2. Serial monitoring of haemostasis through platelet count, prothrombin time, fibrinogen and d-dimers in intensive care unit patients; 3. In patients under therapeutic anticoagulation, monitoring of anti-Xa levels is recommended every 48 hours; 4. Unfractionated heparin or low molecular weight heparin is preferred to fondaparinux or direct oral anticoagulants; 5. Extending prophylactic anticoagulation after hospital discharge in patients with low bleeding risk should be considered.

French experts suggest using an intermediate anticoagulation dose for patients with a body mass index (BMI) over $30 \mathrm{~kg} / \mathrm{m}^{2}$ or with risk factors for DVT. For those with D-dimer levels over $3 \mathrm{ug} / \mathrm{mL}$ and fibrinogen over $8 \mathrm{~g} / \mathrm{L}$ the recommendation is to use the full anticoagulation dose.$^{65} \mathrm{~A}$ Mayo clinic review proposes an intermediate anticoagulation dose for those with BMI over $40 \mathrm{~kg} / \mathrm{m}^{2}$ or D-dimer over 3 $\mathrm{ug} / \mathrm{mL} .^{62}$ These recommendations are controversial due to lack of controlled studies and lack of mention in other expert consensual documents. ${ }^{66,67}$ Observational studies in critical COVID-19 patients found associations between higher dose anticoagulation and a lower risk of death, with a nonsignificant increase in major bleeding. ${ }^{69,70}$ However, this was not observed in a systematic review and meta-analysis. ${ }^{62}$

In COVID-19 patients, an abrupt deterioration in oxygenation should raise suspicion for $\mathrm{PE}$, especially if accompanied by sudden hypotension and tachycardia.

\section{REFERENCES}

1. World Health Organization. WHO Coronavirus Disease (COVID-19) Dashboard. 2020. [accessed 2021 Mar 01]. Available from: https:// covid19. who.int/?gclid=EAlalQobChMI65aDxPW57QIVEJntCh3SxgW wEAAYASAAEgLOZvD_BwE.

2. Zhou P, Yang XL, Wang XG, Hu B, Zhang L, Zhang W, et al. L. A pneumonia outbreak associated with a new coronavirus of probable bat origin. Nature. 2020;579:270-3.

3. Madjid M, Safavi-Naeini P, Solomon SD, Vardeny O. Potential effects of coronaviruses on the cardiovascular system: a review. JAMA Cardiol. 2020;5:831-40.

4. Zhang JJ, Lee KS, Ang LW, Leo YS, Young BE. Risk factors for severe disease and efficacy of treatment in patients infected with COVID-19: a systematic review, meta-analysis, and meta-regression analysis. Clin Infect Dis. 2020;71:2199-206.

5. Guan WJ, Ni ZY, Hu Y, Liang WH, Ou CQ, He JX, et al. Clinical
If CT scan is not feasible, bedside echocardiogram should be performed to assess for cardiac signs of PE. ${ }^{71}$ Yet, the interpretation of echocardiogram findings is ARDS patients can be challenging, especially if there are no previous tests to compare with. Multidisciplinary discussion, integrating all clinical information, is the best strategy for decision making. In patients where PE seems the most likely cause of obstructive shock, thrombolysis should be considered. ${ }^{61,71}$ In patients with suspected PE who are not in shock or bedridden, angio-CT scan is the gold standard. These patients have an indication for full-dose anticoagulation and should be closely monitored for signs of decompensation. ${ }^{71}$

\section{CONCLUSION}

Cardiac complications of COVID-19 are frequent and can weigh heavily on prognosis. Diagnosis is challenging due to confounding factors and logistical hurdles. Multiparametric evaluation of patients, close monitoring and swift action when needed, are of paramount importance. We are only beginning to understand the wider implications of COVID-19 complications. The direct consequences of COVID-19 are becoming clearer, but we should also be wary of the indirect impact, caused by saturation of healthcare systems and decreased response capacity for many months.

\section{AUTHORS CONTRIBUTION}

MT: Conception of the work. Draft of the paper. Critical review of the manuscript.

AHR: Conception of the work. Critical review of the manuscript.

MO: Conception of the work. Draft of the paper. Critical review of the manuscript. Supervision and final approval.

\section{COMPETING INTERESTS}

The authors have declared that no competing interests exist.

\section{FUNDING SOURCES}

This research received no specific grant from any funding agency in the public, commercial, or not-for-profit sectors.

characteristics of coronavirus disease 2019 in China. N Engl J Med. 2020;382:1708-20.

6. Li B, Yang J, Zhao F, Zhi L, Wang X, Liu L, et al. Prevalence and impact of cardiovascular metabolic diseases on COVID-19 in China. Clin Res Cardiol. 2020;109:531-8.

7. Grasselli G, Zangrillo A, Zanella A, Antonelli M, Cabrini L, Castelli A, et al. Baseline characteristics and outcomes of 1591 patients infected with SARS-CoV-2 admitted to ICUs of the Lombardy region, Italy. JAMA. 2020;323:1574-81.

8. Reilev M, Kristensen KB, Pottegard A, Lund LC, Hallas J, Ernst MT, et al. Characteristics and predictors of hospitalization and death in the first 11122 cases with a positive RT-PCR test for SARS-CoV-2 in Denmark: a nationwide cohort. Int J Epidemiol. 2020;49:1468-81.

9. Richardson S, Hirsch J, Narasimhan M, Crawford J, McGinn T, Davidson $\mathrm{KW}$, et al. Presenting characteristics, comorbidities, and outcomes 
among 5700 patients hospitalized with COVID-19 in the New York city area. JAMA. 2020;323:2052-9.

10. Guo T, Fan Y, Chen M, Wu X, Zhang L, He T, et al. Cardiovascular implications of fatal outcomes of patients with coronavirus disease 2019 (COVID-19). JAMA Cardiol. 2020;5:811-8.

11. Libby $P$, Luscher T. COVID-19 is, in the end, an endothelial disease. Eur Heart J. 2020;41:3038-44.

12. Nishiga M, Wang DW, Han Y, Lewis DB, Wu JC. COVID-19 and cardiovascular disease: from basic mechanisms to clinical perspectives. Nat Rev Cardiol. 2020;17:543-58.

13. Guzik TJ, Mohiddin SA, Dimarco A, Patel V, Savvatis K, Marelli-Berg FM, et al. COVID-19 and the cardiovascular system: implications for risk assessment, diagnosis, and treatment options. Cardiovasc Res. 2020;116:1666-87.

14. European Society of Cardiology. ESC Guidance for the Diagnosis and Management of CV Disease during the COVID-19 Pandemic. 2020. [accessed 2020 Dec 15]. Available from: https://www.escardio.org/ Education/COVID-19-and-Cardiology/ESC-COVID-19-Guidance.

15. Shi S, Qin M, Shen B, Cai Y, Liu T, Yang F, et al. Association of cardiac injury with mortality in hospitalized patients with COVID-19 in Wuhan, China. JAMA Cardiol. 2020;5:802-10.

16. Zhou F, Yu T, Du R, Fan G, Liu Y, Liu Z, et al. Clinical course and risk factors for mortality of adult inpatients with COVID-19 in Wuhan, China: a retrospective cohort study. Lancet. 2020;395:1054-62.

17. Sandoval $Y$, Januzzi JL Jr, Jaffe AS. Cardiac troponin for assessment of myocardial injury in COVID-19: JACC Review Topic of the Week. J Am Coll Cardiol. 2020;76:1244-58.

18. Caforio AL, Pankuweit S, Arbustini E, Basso C, Gimeno-Blanes J, Felix SB, et al. European Society of Cardiology Working Group on M and Pericardial D. Current state of knowledge on aetiology, diagnosis, management, and therapy of myocarditis: a position statement of the European Society of Cardiology Working Group on Myocardial and Pericardial Diseases. Eur Heart J. 2013;34:2636-48d.

19. Liu Y, Yang Y, Zhang C, Huang F, Wang F, Yuan J, et al. Clinical and biochemical indexes from 2019-nCoV infected patients linked to viral loads and lung injury. Sci China Life Sci. 2020;63:364-74.

20. Ho JS, Sia CH, Chan MY, Lin W, Wong RC. Coronavirus-induced myocarditis: a meta-summary of cases. Heart Lung. 2020;49:681-5.

21. Inciardi RM, Lupi L, Zaccone G, Italia L, Raffo M, Tomasoni D, et al. Cardiac involvement in a patient with coronavirus disease 2019 (COVID-19). JAMA Cardiol. 2020;5:819-24.

22. $\mathrm{Hu} H, \mathrm{Ma} F$, Wei $X$, Fang $Y$. Coronavirus fulminant myocarditis saved with glucocorticoid and human immunoglobulin. Eur Heart J. 2020;42:206

23. Sardari A, Tabarsi P, Borhany H, Mohiaddin R, Houshmand G. Myocarditis detected after COVID-19 recovery. Eur Heart J Cardiovasc Imaging. 2020;22:131-2.

24. Tavazzi G, Pellegrini C, Maurelli M, Belliato M, Sciutti F, Bottazzi A, et al Myocardial localization of coronavirus in COVID-19 cardiogenic shock. Eur J Heart Fail. 2020;22:911-5.

25. Araiza-Garaygordobil D, Montalto C, Martinez-Amezcua P, CabelloLopez A, Gopar-Nieto R, Alabrese R, et al. Impact of the COVID-19 pandemic on hospitalizations for acute coronary syndromes: a multinational study. QJM. 2021. Advance article. [accessed $2021 \mathrm{Fev}$ 26]. Available from: https://pubmed.ncbi.nlm.nih.gov/33486512/.

26. Einstein AJ, Shaw LJ, Hirschfeld C, Williams MC, Villines TC, Better $\mathrm{N}$, et al. International impact of COVID-19 on the diagnosis of heart disease. J Am Coll Cardiol. 2021;77:173-85

27. Tam CF, Cheung KS, Lam S, Wong A, Yung A, Sze M, et al. Impact of coronavirus disease 2019 (COVID-19) outbreak on outcome of myocardial infarction in Hong Kong, China. Catheter Cardiovasc Interv. 2020;97:E194-7.

28. Bangalore S, Sharma A, Slotwiner A, Yatskar L, Harari R, Shah B, et al. ST-segment elevation in patients with Covid-19 - a case series. N Engl J Med. 2020;382:2478-80

29. Stefanini GG, Montorfano M, Trabattoni D, Andreini D, Ferrante $\mathrm{G}$, Ancona $\mathrm{M}$, et al. ST-elevation myocardial infarction in patients with COVID-19: clinical and angiographic outcomes. Circulation. 2020;141:2113-6.

30. Barghash MH, Pinney SP. Heart failure in the COVID-19 pandemic: where has all New York's congestion gone? J Card Fail. 2020;26:477-8.

31. Andersson C, Gerds T, Fosbol E, Phelps M, Andersen J, Lamberts M, et al. Incidence of new-onset and worsening heart failure before and after the COVID-19 epidemic lockdown in Denmark: a nationwide cohort study. Circ Heart Fail. 2020;13:e007274.

32. Cleland JG, Clark RA, Pellicori P, Inglis SC. Caring for people with heart failure and many other medical problems through and beyond the COVID-19 pandemic: the advantages of universal access to home telemonitoring. Eur J Heart Fail. 2020;22:995-8.

33. Mehra MR, Ruschitzka F. COVID-19 illness and heart failure: a missing link? JACC Heart Fail. 2020;8:512-4.

34. Bader F, Manla Y, Atallah B, Starling RC. Heart failure and COVID-19. Heart Fail Rev. 2020;26:1-10

35. Gao L, Jiang D, Wen XS, Cheng XC, Sun M, He B, et al. Prognostic value of NT-proBNP in patients with severe COVID-19. Respir Res. 2020;21:83.

36. Morales DR, Conover MM, You SC, Pratt N, Kostka K, Duarte-Salles $\mathrm{T}$, et al. Renin-angiotensin system blockers and susceptibility to COVID-19: an international, open science, cohort analysis. Lancet Digit Health. 2021;3:e98-114.

37. Hippisley-Cox J, Young D, Coupland C, Channon KM, Tan PS, Harrison DA, et al. Risk of severe COVID-19 disease with ACE inhibitors and angiotensin receptor blockers: cohort study including 8.3 million people. Heart. 2020;106:1503-11.

38. Lopes R, Macedo A, de Barros E, Silva P, Moll-Bernardes R, Dos Santos $\mathrm{TM}$, et al. Effect of discontinuing vs continuing angiotensin-converting enzyme inhibitors and angiotensin II receptor blockers on days alive and out of the hospital in patients admitted with COVID-19: a randomized clinical trial. JAMA. 2021;325:254-64

39. Desai HD, Jadeja DM, Sharma K. Takotsubo syndrome a rare entity in patients with COVID-19: an updated review of case-reports and caseseries. Int J Cardiol Heart Vasc. 2020;29:100604

40. Jabri A, Kalra A, Kumar A, Alameh A, Adroja S, Bashir H, et al. Incidence of stress cardiomyopathy during the coronavirus disease 2019 pandemic. JAMA Netw Open. 2020;3:e2014780.

41. Ghadri J, Wittstein IS, Prasad A, Sharkey S, Dote K, Akashi YJ, et al. International Expert Consensus Document on Takotsubo Syndrome (Part I): Clinical Characteristics, Diagnostic Criteria, and Pathophysiology. Eur Heart J. 2018;39:2032-46.

42. Ghadri JR, Wittstein IS, Prasad A, Sharkey S, Dote K, Akashi YJ, et al. International Expert Consensus Document on Takotsubo Syndrome (Part II): Diagnostic Workup, Outcome, and Management. Eur Heart J. 2018;39:2047-62.

43. Faraj R, Belkhayat C, Bouchlarhem A, El Aidouni G, Bkiyar H, Housni B. Acute pericarditis revealing COVID-19 infection: case report. Ann Med Surg. 2021;62:225-7.

44. Kumar R, Kumar J, Daly C, Edroos S. Acute pericarditis as a primary presentation of COVID-19. BMJ Case Rep. 2020;13:e237617.

45. Imazio M, Brucato A, Lazaros G, Andreis A, Scarsi M, Klein A, et al. Anti-inflammatory therapies for pericardial diseases in the COVID-19 pandemic: safety and potentiality. J Cardiovasc Med. 2020;21:625-9.

46. Bhatla A, Mayer M, Adusumalli S, Hyman M, Oh E, Tierney A, et al. COVID-19 and cardiac arrhythmias. Heart Rhythm. 2020;17:1439-44.

47. Wang Y, Wang Z, Tse G, Zhang L, Wan EY, Guo Y, et al. Cardiac arrhythmias in patients with COVID-19. J Arrhythm. 2020;36:827-36.

48. Mai F, Del Pinto R, Ferri C. COVID-19 and cardiovascular diseases. J Cardiol. 2020;76:453-8.

49. Harrison S, Fazio-Eynullayeva S, Lane D, Underhill P, Lip G. Atrial fibrillation and the risk of 30-day incident thromboembolic events, and mortality in adults $\geq 50$ years with COVID-19. J Arryhtmia. 2021;37:6.

50. Bernardini A, Ciconte G, Negro G, Rondine R, Mecarocci V, Viva T, et al. Assessing QT interval in COVID-19 patients: safety of hydroxychloroquine-azithromycin combination regimen. Int $\mathrm{J}$ Cardiol. 2020;324:242-8.

51. Baldi E, Sechi GM, Mare C, Canevari F, Brancaglione A, Primi R, et al, Lombardia CR. Out-of-hospital cardiac arrest during the Covid-19 outbreak in Italy. N Engl J Med. 2020;383:496-8.

52. Baldi E, Sechi G, Mare C, Canevari F, Brancaglione A, Primi R, et al. COVID-19 kills at home: the close relationship between the epidemic and the increase of out-of-hospital cardiac arrests. Eur Heart J. 2020;41:3045-54

53. Fothergill RT, Smith AL, Wrigley F, Perkins GD. Out-of-hospital cardiac arrest in London during the COVID-19 pandemic. Resusc Plus 2021;5:100066.

54. Lai PH, Lancet EA, Weiden MD, Webber MP, Zeig-Owens R, Hall CB et al. Characteristics associated with out-of-hospital cardiac arrests and resuscitations during the novel coronavirus disease 2019 pandemic in New York City. JAMA Cardiol. 2020;5:1154-63.

55. Grillet F, Behr J, Calame P, Aubry S, Delabrousse E. Acute pulmonary embolism associated with COVID-19 pneumonia detected with pulmonary CT angiography. Radiology. 2020;296:E186-8.

56. Leonard-Lorant I, Delabranche X, Severac F, Helms J, Pauzet C, Collange $\mathrm{O}$, et al. Acute pulmonary embolism in patients with COVID-19 
at CT angiography and relationship to d-dimer levels. Radiology. 2020;296:E189-91.

57. Beun R, Kusadasi N, Sikma M, Westerink J, Huisman A. Thromboembolic events and apparent heparin resistance in patients infected with SARSCoV-2. Int J Lab Hematol. 2020;42:19-20.

58. Helms J, Tacquard C, Severac F, Leonard-Lorant I, Ohana M Delabranche $X$, et al. High risk of thrombosis in patients with severe SARS-CoV-2 infection: a multicenter prospective cohort study. Intensive Care Med. 2020;46:1089-98.

59. Wichmann D, Sperhake JP, Lutgehetmann M, Steurer S, Edler C, Heinemann A, et al. Autopsy findings and venous thromboembolism in patients with COVID-19: a prospective cohort study. Ann Intern Med. 2020;173:268-77.

60. Bunce PE, High SM, Nadjafi M, Stanley K, Liles WC, Christian MD. Pandemic H1N1 influenza infection and vascular thrombosis. Clin Infect Dis. 2011;52:e14-7.

61. Bikdeli B, Madhavan MV, Jimenez D, Chuich T, Dreyfus I, Driggin E, e al. COVID-19 and thrombotic or thromboembolic disease: implications for prevention, antithrombotic therapy, and follow-up: JACC state-of-theart review. J Am Coll Cardiol. 2020;75:2950-73.

62. McBane RD $2^{\text {nd }}$, Torres Roldan VD, Niven AS, Pruthi RK, Franco PM, Linderbaum JA, et al. Anticoagulation in COVID-19: a systematic review, meta-analysis, and rapid guidance from Mayo Clinic. Mayo Clin Proc. 2020;95:2467-86.

63. Tang N, Li D, Wang X, Sun Z. Abnormal coagulation parameters are associated with poor prognosis in patients with novel coronavirus pneumonia. J Thromb Haemost. 2020;18:844-7.

64. Sakr Y, Giovini M, Leone M, Pizzilli G, Kortgen A, Bauer M, et al. Pulmonary embolism in patients with coronavirus disease-2019
(COVID-19) pneumonia: a narrative review. Ann Intensive Care. 2020;10:124.

65. Susen S, Tacquard CA, Godon A, Mansour A, Garrigue D, Nguyen P, et al . Prevention of thrombotic risk in hospitalized patients with COVID-19 and hemostasis monitoring. Crit Care. 2020;24:364.

66. Marietta M, Ageno W, Artoni A, De Candia E, Gresele P, Marchetti M, et al. COVID-19 and haemostasis: a position paper from Italian Society on Thrombosis and Haemostasis (SISET). Blood Transfus. 2020;18:167-9.

67. Moores LK, Tritschler T, Brosnahan S, Carrier M, Collen JF, Doerschug $\mathrm{K}$, et al. Prevention, diagnosis, and treatment of VTE in patients with coronavirus disease 2019: CHEST Guideline and Expert Panel Report. Chest. 2020;158:1143-63.

68. Spyropoulos AC, Levy JH, Ageno W, Connors JM, Hunt BJ, Iba T, et al. Scientific and Standardization Committee communication: clinical guidance on the diagnosis, prevention, and treatment of venous thromboembolism in hospitalized patients with COVID-19. J Thromb Haemost. 2020;18:1859-65.

69. Paranjpe I, Fuster V, Lala A, Russak AJ, Glicksberg BS, Levin MA et al. Association of treatment dose anticoagulation with in-hospital survival among hospitalized patients with COVID-19. J Am Coll Cardiol. 2020;76:122-4.

70. Jonmarker S, Hollenberg J, Dahlberg M, Stackelberg O, Litorell J, Everhov $\mathrm{AH}$, et al. Dosing of thromboprophylaxis and mortality in critically ill COVID-19 patients. Crit Care. 2020;24:653.

71. Konstantinides SV, Meyer G, Becattini C, Bueno H, Geersing GJ, Harjola VP, et al. 2019 ESC Guidelines for the Diagnosis and Management of Acute Pulmonary Embolism Developed in Collaboration with the European Respiratory Society (ERS). Eur Heart J. 2020;41:543-603. 